๑ Open Access Full Text Article

\title{
Improvement in Lung Function and Patient-Reported Outcomes in Patients with COPD with Comorbid Anxiety and Depression Receiving Nebulized Glycopyrrolate in the GOLDEN 3 and 4 Studies
}

This article was published in the following Dove Press journal:

International Journal of Chronic Obstructive Pulmonary Disease

\author{
Nicola A Hanania' \\ Abebaw M Yohannes (D) ${ }^{2}$ \\ Ayca Ozol-Godfrey ${ }^{3}$ \\ Michael Tocco ${ }^{3}$ \\ Thomas Goodin ${ }^{3}$ \\ Sanjay Sharma $\mathbb{D D}^{3}$ \\ Shahin Sanjar $\mathbb{D}^{3}$ \\ 'Section of Pulmonary, Critical Care and \\ Sleep Medicine, Baylor College of \\ Medicine, Houston, TX, 77030, USA; \\ ${ }^{2}$ Department of Physical Therapy, Azusa \\ Pacific University, Azusa, CA, USA; \\ ${ }^{3}$ Sunovion Pharmaceuticals Inc., \\ Marlborough, MA, USA
}

Background: Anxiety and depression (A/D) are common in patients with chronic obstructive pulmonary disease (COPD) and are often associated with lower adherence to treatment and worse patient-related outcomes. However, studies on the impact of comorbid A/D on responses to bronchodilators are limited.

Methods: This post hoc analysis of pooled data $(\mathrm{N}=861)$ from the GOLDEN 3 and 4 studies compared the efficacy and safety of nebulized glycopyrrolate (GLY) $25 \mu \mathrm{g}$ in patients with moderate-to-very-severe COPD, grouped by self-reported A/D. Changes in forced expiratory volume in 1 second $\left(\mathrm{FEV}_{1}\right)$ and health-related quality of life determined by St George's Respiratory Questionnaire (SGRQ) scores in patients with or without comorbid A/D (A/D [+] or A/D [-]) were examined following 12 weeks of GLY $25 \mu \mathrm{g}$ twice-daily (BID) or placebo treatment.

Results: A/D (+) patients were predominantly female, younger, included a higher proportion of current smokers, and had higher baseline SGRQ scores compared with the A/D (-) group. At 12 weeks, GLY resulted in placebo-adjusted improvements from baseline in $\mathrm{FEV}_{1}$ of $46.9 \mathrm{~mL}(\mathrm{p}=0.19$; not significant) and $106.7 \mathrm{~mL}(\mathrm{p}<0.0001)$, in the $\mathrm{A} / \mathrm{D}(+)$ and $\mathrm{A} / \mathrm{D}(-)$ groups, respectively. Improvements were observed with GLY compared to placebo in SGRQ scores, regardless of baseline A/D status; the placebo-adjusted least squares mean change from baseline in SGRQ total scores was $-3.16(\mathrm{p}>0.05)$ and $-3.34(\mathrm{p}<0.001)$, for the A/D $(+)$ and A/D (-) groups, respectively. Despite numerical improvements in SGRQ scores with GLY in the A/D (+) group, a higher response to placebo was observed. GLY was generally well tolerated throughout 12 weeks of treatment; incidence of adverse events was higher in the $\mathrm{A} / \mathrm{D}(+)$ group compared with the $\mathrm{A} / \mathrm{D}(-)$ group in both treatment arms.

Conclusion: GLY $25 \mu \mathrm{g}$ BID resulted in numerical improvements in FEV ${ }_{1}$, SGRQ total scores and SGRQ responder rates in patients with moderate-to-very-severe COPD, regardless of $\mathrm{A} / \mathrm{D}$ status at baseline; significant improvements were noted only in the $\mathrm{A} / \mathrm{D}(+)$ group. The results emphasize the importance of considering underlying comorbidities including $\mathrm{A} / \mathrm{D}$ when evaluating the efficacy of COPD treatments.

Keywords: anxiety, COPD, depression, LAMA, nebulized glycopyrrolate

\section{Background}

Section of Pulmonary, Critical Care and

Sleep Medicine, Baylor College of

Medicine, Houston, TX, USA

Tel +I 7|3-873-3454

Email hanania@bcm.edu
Chronic obstructive pulmonary disease (COPD) is a progressive disease characterized by persistent respiratory symptoms and airflow limitation. ${ }^{1}$ Patients with COPD commonly present with one or more coexisting comorbidities that can 
impair their quality of life, and may increase their risk for morbidity and premature mortality. ${ }^{2,3}$ Anxiety and depression (A/D) are common comorbidities in patients with COPD, occurring more frequently compared with the general population, and are often associated with poor COPD outcomes. ${ }^{4-6}$ Comorbid A/D in COPD has been associated with lower treatment adherence and increased risk of COPD exacerbations, morbidity, disability, early dropout from pulmonary rehabilitation, and mortality. ${ }^{7-11}$ A crosssectional analysis performed in 408 patients with COPD showed that $\mathrm{A} / \mathrm{D}$ had the most impact on health status, as measured by the Feeling Thermometer, a patient-reported health status instrument. ${ }^{12}$ Comorbid A/D is often observed in patients with COPD, with an estimated prevalence ranging from $22 \%$ to $48 \% .^{13,14}$ Despite its high prevalence and overall negative impact on COPD outcomes, most studies that characterize the impact of $\mathrm{A} / \mathrm{D}$ on COPD outcomes study these comorbidities separately; few studies have explored the impact of comorbid A/D on patient-reported outcomes (PROs) in COPD. ${ }^{13,15}$ However, the impact of comorbid $\mathrm{A} / \mathrm{D}$ on responses to bronchodilator therapy in COPD has not been characterized.

Glycopyrrolate inhalation solution (GLY; Lonhala ${ }^{\circledR}$, Sunovion Pharmaceuticals Inc., Marlborough, MA, USA) $25 \mu \mathrm{g}$ twice daily (BID) delivered by the eFlow ${ }^{\circledR}$ Closed System (CS) nebulizer (Magnair ${ }^{\circledR}$, PARI Pharma GmbH, Starnberg, Germany) was approved by the US Food and Drug Administration (FDA) for the long-term maintenance treatment of airflow obstruction in patients with COPD in December $2017 .{ }^{16}$ This approval was based, in part, on the 12-week, replicate, Glycopyrrolate for Obstructive Lung Disease via Electronic Nebulizer (GOLDEN) 3 and 4 studies, in which GLY demonstrated statistically significant and clinically important improvements in lung function and St George's Respiratory Questionnaire (SGRQ) scores compared with placebo in patients with moderate-to -very-severe COPD, with no major safety signals. ${ }^{17}$

Analysis of pooled data from the 12-week GOLDEN 3 and 4 studies was conducted to evaluate the effect of GLY $25 \mu \mathrm{g}$ BID treatment on lung function and SGRQ scores in COPD patients with comorbid A/D. Given the high prevalence of $\mathrm{A} / \mathrm{D}$ in patients with $\mathrm{COPD}$, determining its impact on COPD treatment outcomes may provide insight into treatment strategies. The aim of this post hoc analysis was to investigate the impact of self-reported comorbid A/D on response to bronchodilators among patients with COPD.

\section{Methods}

\section{Study Design}

This is a post hoc analysis of pooled data from the GOLDEN 3 and 4 studies, details for which have been described previously (Figure 1). ${ }^{17}$ Briefly, in the 12 -week, multicenter, placebo-controlled, double-blind studies, patients $(\mathrm{N}=1293)$ were randomized in a 1:1:1 ratio to receive placebo or GLY (25 or $50 \mu \mathrm{g}$ BID), via the eFlow $^{\circledR}$ CS nebulizer. Randomization in each study was stratified by background long-acting $\beta_{2}$-agonist (LABA) use (yes/no) and by cardiovascular (CV) risk (high/low). Ipratropium bromide, as supplemental medication, and albuterol (salbutamol), as rescue medication, were permitted. Data for the GLY $50 \mu \mathrm{g}$ BID treatment arm are not presented in this post hoc analysis, as $25 \mu \mathrm{g}$ is the FDA-approved dose.

To perform the post hoc analysis, pooled patient data from the GOLDEN 3 and 4 studies were categorized into those with or without comorbid A/D $(\mathrm{A} / \mathrm{D}[+]$ and A/D [-] groups). $\mathrm{A} / \mathrm{D}(+)$ patients had a self-reported medical history of $A / D \geq 6$ months prior to and ongoing at the first study treatment. A/D (-) patients may have: 1) no history of anxiety or depression, 2) anxiety alone or 3 ) depression alone; patients in this group did not concurrently have both disorders. $\mathrm{A} / \mathrm{D}$ in the medical history was noted via patient self-report or available medical records. If the sites did not use electronic medical records, patient self-reporting of A/D was accepted.

The GOLDEN 3 (SUN101-301: project approval number 28481) and GOLDEN 4 (SUN101-302: project approval number 28482) study protocols were approved by Quorum Review IRB North American (US and Canadian) Board (Panel II) prior to patient enrollment and were conducted in accordance with the protocols, International Council for Harmonization Good Clinical Practice guidelines, and the Declaration of Helsinki. All patients provided written informed consent.

\section{Patients}

The study protocols including inclusion and exclusion criteria have been previously published. ${ }^{17}$ Briefly, patients included males or females $\geq 40$ years of age, current or ex-smokers with $\geq 10$ pack-year smoking history, and a clinical diagnosis of moderate-to-very-severe COPD (as defined by GOLD criteria). ${ }^{1}$ Spirometry assessments were performed using a standardized, computer-based pneumotach spirometry system, and included the determination of forced expiratory volume in 


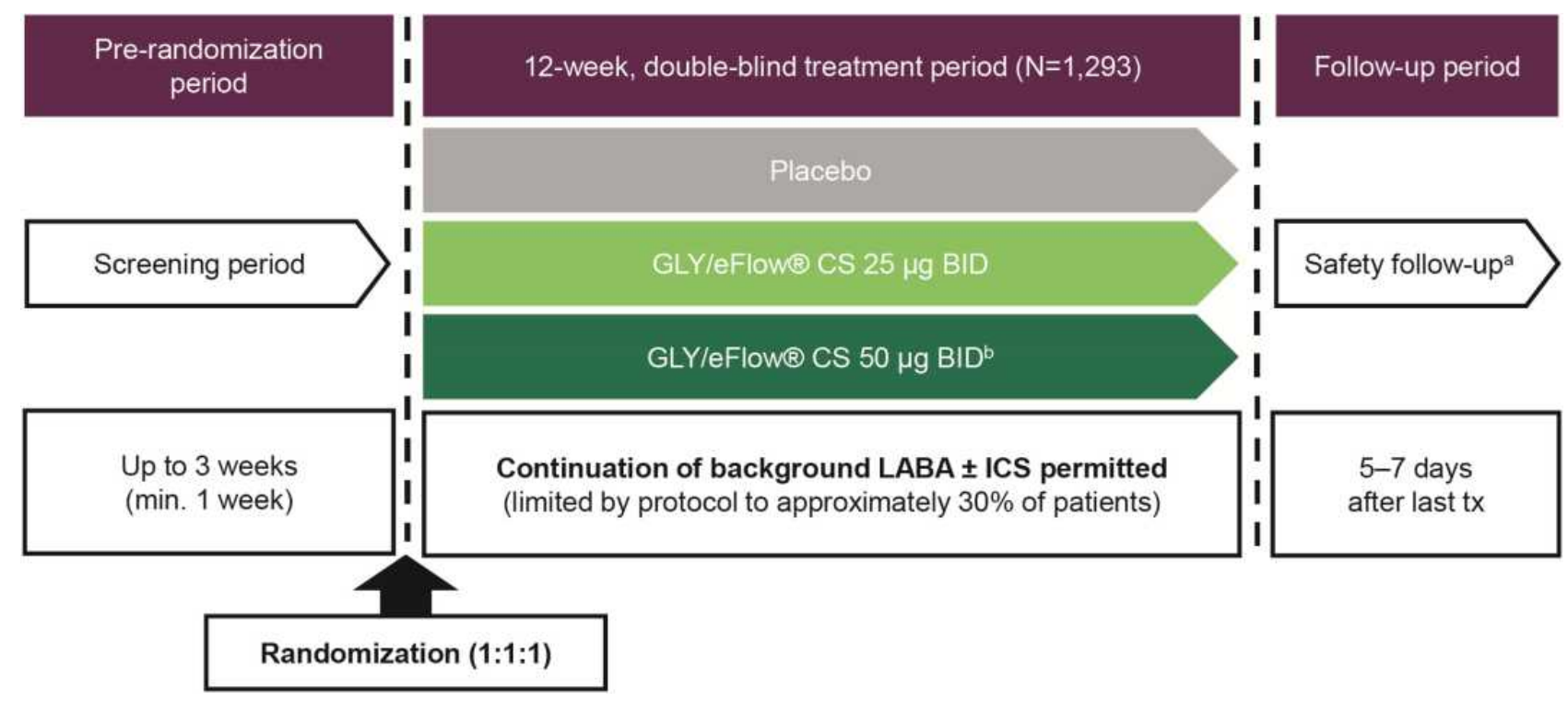

Figure I GOLDEN 3 and 4 study designs.

Notes: Data from Kerwin et al. ${ }^{17}$ aSAEs were monitored for 30 days after the last dose of study treatment. ${ }^{b}$ Data for the GLY $50 \mu g$ BID treatment arm are not presented in this post hoc analysis.

Abbreviations: BID, twice daily; CS, closed system; GLY, nebulized glycopyrrolate; ICS, inhaled corticosteroids; LABA, long-acting $\beta_{2}$-agonist; min, minimum; SAE, serious adverse event; tx, treatment.

1 second $\left(\mathrm{FEV}_{1}\right)$, forced vital capacity $(\mathrm{FVC})$, and $\mathrm{FEV}_{1}$ /FVC ratios. Predicted $\mathrm{FEV}_{1}$ was obtained using the normal prediction equations from the 3rd National Health and Nutrition Examination Survey (NHANES III 2001). ${ }^{18}$ Spirometry measurements were conducted in accordance with the current ATS/ERS 2005 guidelines. ${ }^{19}$ Additionally, post-bronchodilator (ipratropium $68 \mu \mathrm{g}$ ) spirometry qualifying criteria at screening included $\mathrm{FEV}_{1}<80 \%$ of predicted normal, $\mathrm{FEV}_{1}>0.7$ $\mathrm{L}$ and $\mathrm{FEV}_{1} / \mathrm{FVC}<0.70$.

\section{Statistical Analyses}

This analysis compared GLY and placebo treatment in patients grouped by comorbid A/D status on the following endpoints: change from baseline in trough $\mathrm{FEV}_{1}$ (trough $\mathrm{FEV}_{1}$ is measured before dosing at each documented visit) and the changes from baseline in SGRQ total and domain scores at Week 12. Safety data were analyzed using descriptive statistics; ${ }^{17}$ adverse events (AEs) and serious adverse events (SAEs) were coded according to MedDRA v15.1 and summarized by treatment, system organ class, and preferred term.

This study focused on data with the FDA-approved dose of $25 \mu \mathrm{g}$ BID of GLY. ${ }^{16}$ To stay consistent with the new drug application submitted to the FDA for Lonhala ${ }^{\circledR}$ Magnair ${ }^{\circledR}$, changes from baseline in trough $\mathrm{FEV}_{1}$ at Week 12 were analyzed using a mixed-model for repeated measures, with factors for treatment group, CV risk (high/low), visit week, background LABA use (yes/no), and visit week by treatment group interaction, and baseline $\mathrm{FEV}_{1}$ as a covariate. Unstructured covariance was used to model the intra-subject variability. Changes from baseline in SGRQ scores at Week 12 were analyzed by analysis of covariance. SGRQ responders, defined as the proportions of patients with reduction in SGRQ total score $\geq 4$ units, ${ }^{20}$ which represents the minimum clinically important difference (MCID), were analyzed using a logistic regression model. Both SGRQ analyses included treatment group, CV risk (high/low), and background LABA use (yes/ no), with baseline SGRQ as covariates. Efficacy analyses used the intent-to-treat (ITT) population and the safety analyses were conducted using the safety population; both populations consisted of all randomized patients who received $\geq 1$ dose of study drug (on-treatment data). No multiplicity adjustments were made for the post hoc multiple comparisons. All p-value interpretations were made at the 5\% significance level. All statistical procedures were performed using $\mathrm{SAS}^{\circledR}$ v9.2 or higher (SAS Institute Inc., Cary, NC).

\section{Results}

\section{Patient Demographics and Baseline Characteristics}

Pooled data from patients $(\mathrm{N}=861)$ receiving placebo or GLY $25 \mu \mathrm{g}$ BID in GOLDEN 3 and 4 were grouped based 
Table I Patient Distribution by Baseline Comorbid Anxiety and Depression Status

\begin{tabular}{|l|c|c|c|}
\hline Patients, n (\%) & $\begin{array}{c}\text { Total } \\
\text { N=86 I }\end{array}$ & $\begin{array}{c}\text { Placebo } \\
\text { N=430 }\end{array}$ & $\begin{array}{c}\text { GLY 25 } \mu \text { Bg BID } \\
\text { N=43 I }\end{array}$ \\
\hline A/D (+) & $156(18.1)$ & $75(17.4)$ & $81(18.8)$ \\
\hline A/D (-) & $705(8 I .9)$ & $355(82.6)$ & $350(8 I .2)$ \\
Anxiety only & $75(8.7)$ & $37(8.6)$ & $38(8.8)$ \\
Depression only & I4I (16.4) & $73(17.0)$ & $68(15.8)$ \\
\hline
\end{tabular}

Abbreviations: A/D (+), comorbid anxiety and depression; A/D (-), no comorbid anxiety and depression, or anxiety or depression alone; BID, twice daily; GLY, nebulized glycopyrrolate.

on the presence or absence of comorbid A/D (Table 1). A high prevalence of anxiety, depression or both was observed in the patient population (372 patients; $43.2 \%$ ). $\mathrm{A} / \mathrm{D}(+)$ patients represented $18.1 \%$ of the COPD patient population $(n=156)$. Among A/D $(-)$ patients $(n=705), 75$ $(8.7 \%)$ patients had anxiety alone and 141 (16.4\%) patients had depression alone (Table 1).

Baseline demographics and disease characteristics are presented in Table 2. A comparison of patient characteristics at baseline showed that A/D $(+)$ patients were predominantly female ( $\sim 66 \%$ vs $\sim 40 \%$ ), younger ( $\sim 71 \%$ vs $48 \%$ were $<65$ years of age), and with a higher proportion of current smokers $(71 \%$ vs $49 \%)$, in the A/D (+) vs A/D (-) groups, respectively. In the $\mathrm{A} / \mathrm{D}(+)$ group, the background use of LABA and ICS was lower among patients receiving placebo, compared to those receiving GLY; in the A/D (-) group, background use of LABA and ICS was similar between treatment groups. The baseline SGRQ total and domain scores were higher in the A/D (+) patients.

\section{Efficacy}

\section{Lung Function}

At Week 12, GLY resulted in significant improvement $(\mathrm{p}<0.0001)$ in trough $\mathrm{FEV}_{1}$ from baseline in the A/D (-) group, compared with placebo. The least squares [LS] mean (standard error [SE]) for the change from baseline in trough $\mathrm{FEV}_{1}$ for the GLY $25 \mu \mathrm{g}$ and placebo groups were 98.6 (11.6) $\mathrm{mL}$ and -8.1 (11.6) $\mathrm{mL}$, respectively (placeboadjusted change from baseline was 106.7 [16.0] $\mathrm{mL}$, $\mathrm{p}<0.0001$; Figure 2). Among the A/D (+) patients, the LS mean (SE) changes from baseline in trough $\mathrm{FEV}_{1}$ were 33.6 (24.4) $\mathrm{mL}$ and -13.3 (27.7) $\mathrm{mL}$ with GLY $25 \mu \mathrm{g}$ and placebo groups, respectively; in $\mathrm{A} / \mathrm{D}(+)$ patients, the trough $\mathrm{FEV}_{1}$ improvements from baseline observed with GLY were not significant compared to placebo (placeboadjusted change from baseline was 46.9 [35.7] $\mathrm{mL}, \mathrm{p}=0.19$ ).

\section{Health-Related Quality of Life (HRQoL) - SGRQ Scores and Responder Analyses}

At 12 weeks, significant improvements compared with placebo in the SGRQ total scores following treatment with GLY $25 \mu \mathrm{g}$ BID occurred only in the A/D (-) group; the placebo-adjusted LS mean (SE) change from baseline in SGRQ total scores for this group was -3.34 (0.86) $(\mathrm{p}<0.001$; Figure $3 \mathrm{~A})$. This pattern was consistent across all of the SGRQ domain scores in the A/D (-) group, with the greatest changes observed in the symptoms domain score (Figure 3B-D).

In the $\mathrm{A} / \mathrm{D}(+)$ group, the magnitude of improvements in SGRQ total and domain scores with GLY were greater than those observed in the A/D (-) group. However, the placebo response among patients in the A/D (+) group was markedly high compared with that in the A/D (-) group and resulted in reduced placebo-adjusted changes from baseline in SGRQ total scores. The LS mean (SE) change from baseline in SGRQ total scores in the A/D (+) group was -5.77 (1.52) and -2.61 (1.57) for the GLY $25 \mu \mathrm{g}$ and placebo groups, respectively $(\mathrm{p}=0.12$; Figure $3 \mathrm{~A})$. A similar trend of high placebo response was also observed in the SGRQ domain scores in the A/D (+) group (Figure 3B-D) and was highest with the symptoms domain with the LS mean (SE) change from baseline of -7.36 (2.18) and -4.57 (2.27) for the GLY $25 \mu \mathrm{g}$ and placebo groups, respectively (Figure 3D).

The odds of being an SGRQ responder ( $\geq 4$-unit reduction) in the GLY treatment group were significantly greater than placebo $(\mathrm{p}<0.01)$ in patients in the A/D $(-)$ group but not in the $\mathrm{A} / \mathrm{D}(+)$ groups, although the proportion of responders was numerically greater than placebo in both groups (Figure 4).

\section{Safety}

Overall, GLY was generally well tolerated, regardless of comorbid A/D disorder status (Table 3). In both treatment arms, overall incidence of AEs was higher in the A/D (+) group (GLY: 54.3\%; Placebo: 66.7\%), compared with the A/D (-) group (GLY: 40.9\%; Placebo: $49.3 \%$ ). Importantly, the incidence of overall AEs was lower in the GLY treatment arm compared with placebo in both comorbid A/D groups. Cough and worsening of COPD were the most common AEs reported across all 
Table 2 Patient Demographics and Baseline Characteristics by Baseline Comorbid Anxiety and Depression Status

\begin{tabular}{|c|c|c|c|c|}
\hline \multirow[t]{2}{*}{ Parameter } & \multicolumn{2}{|c|}{ A/D (+) } & \multicolumn{2}{|c|}{ A/D (-) } \\
\hline & Placebo $\mathbf{N}=75$ & GLY $25 \mu$ g BID N=8I & Placebo $N=355$ & GLY $25 \mu \mathrm{g}$ BID $N=350$ \\
\hline Age, years, median (range) & $60.0(42-8 I)$ & $59.0(45-79)$ & $65.0(4 \mid-84)$ & $64.5(40-83)$ \\
\hline$<65$ years, $\mathrm{n}(\%)$ & $54(72.0)$ & $56(69.1)$ & $166(46.8)$ & $175(50.0)$ \\
\hline$\geq 65$ years, $\mathrm{n}(\%)$ & $21(28.0)$ & $25(30.9)$ & $189(53.2)$ & $175(50.0)$ \\
\hline Female, n (\%) & $5 I(68.0)$ & $52(64.2)$ & $144(40.6)$ & $137(39.1)$ \\
\hline White, n (\%) & $72(96.0)$ & $76(93.8)$ & $316(89.0)$ & $309(88.3)$ \\
\hline BMI, $\mathrm{kg} / \mathrm{m}^{2}$ median (range) & $29.12(17.9-48.9)$ & $28.98(16.5-47.1)$ & $28.07(|6.3-7| .6)$ & $26.96(14.7-53.4)$ \\
\hline Current smoker, n (\%) & $55(73.3)$ & $56(69.1)$ & $163(45.9)$ & $184(52.6)$ \\
\hline Pack years, median (range) & $45.0(11-188)$ & $46.0(16-129)$ & $47.0(10-240)$ & $45.5(10-192)$ \\
\hline High CV risk, n (\%) & $52(69.3)$ & $56(69.1)$ & $226(63.7)$ & $219(62.6)$ \\
\hline Background LABA, n (\%) & $18(24.0)$ & $26(32.1)$ & $114(32.1)$ & $109(31.1)$ \\
\hline Background ICS, n (\%) & $17(22.7)$ & $26(32.1)$ & $110(31.0)$ & $100(28.6)$ \\
\hline COPD exacerbation within past 12 months, $\mathrm{n}(\%)$ & $17(22.7)$ & $17(2 \mid .0)$ & $76(21.4)$ & $67(19.1)$ \\
\hline $\mathrm{FEV}_{\mathrm{l}}, \mathrm{L}$, median (range) ${ }^{\mathrm{a}}$ & $1.345(0.59-2.49)$ & $1.288(0.53-3.07)$ & $1.260(0.5 I-3.15)$ & $1.255(0.475-3.23)$ \\
\hline $\mathrm{FEV}_{\text {, reversibility, } \% \text {, median (range) }}^{\mathrm{b}}$ & $18.0(-2-58)$ & $16.0(-8-63)$ & $15.0(-33-86)$ & $17.0(-16-74)$ \\
\hline \multicolumn{5}{|l|}{ Post-bronchodilator $\mathrm{FEV}_{1}, \mathrm{n}(\%)^{\mathrm{c}}$} \\
\hline$<30 \%$ predicted & $2(2.7)$ & $2(2.5)$ & $22(6.2)$ & $27(7.7)$ \\
\hline$\geq 30 \%-<50 \%$ predicted & $22(29.3)$ & $28(34.6)$ & $|3|(36.9)$ & $128(36.7)$ \\
\hline$\geq 50 \%$ predicted & $51(68.0)$ & $51(63.0)$ & $202(56.9)$ & $194(55.6)$ \\
\hline SGRQ total score, median (range) ${ }^{d}$ & $53.29(22.20-88.21)$ & $56.73(9.11-90.09)$ & $46.05(1.13-98.21)$ & $47.83(0-95.94)$ \\
\hline Activity component ${ }^{\mathrm{e}}$ & $72.82(60.20-85.84)$ & $73.37(59.46-85.84)$ & $66.19(49.54-79.67)$ & $66.19(47.70-79.67)$ \\
\hline Impacts component $^{f}$ & $39.72(25.02-53.51)$ & $41.68(28.57-53.22)$ & $30.72(16.99-46.76)$ & $33.63(19.26-47.96)$ \\
\hline Symptoms component ${ }^{\mathrm{g}}$ & $69.06(53.16-81.03)$ & 73.2 (57.3I-80.9I) & $61.6(42.90-74.90)$ & $64.18(46.14-79.70)$ \\
\hline
\end{tabular}

Notes: ${ }^{a} A / D(+)$, Placebo: $n=69, G L Y: n=78 ; A / D(-)$, Placebo: $n=346, G L Y: n=331 .{ }^{b} A / D(+)$, Placebo: $n=75, G L Y: n=81 ; A / D(-)$, Placebo: $n=355, G L Y: n=349 .{ }^{c} O n e$ patient in the $A / D(-)$ group treated with GLY had missing post-bronchodilator FEV, data. ${ }^{d} A / D(+)$, Placebo: $n=72, G L Y: n=75 ; A / D(-)$, Placebo: $n=338, G L Y: n=332 .{ }^{e} A / D(+)$, Placebo: $n=72, G L Y: n=76 ; A / D(-)$, Placebo: $n=337, G L Y: n=331 .{ }^{f} A / D(+)$, Placebo: $n=72, G L Y: n=76 ; A / D(-)$, Placebo: $n=339, G L Y: n=332 .{ }^{8} A / D(+)$, Placebo: $n=73, G L Y:$ $n=76 ; A / D(-)$, Placebo: $n=345, G L Y: n=335$.

Abbreviations: A/D (+), comorbid anxiety and depression; A/D (-), no comorbid anxiety and depression, or anxiety or depression alone; BID, twice daily; BMI, body mass index; CV, cardiovascular; FEV , forced expiratory volume in I second; GLY, nebulized glycopyrrolate; ICS, inhaled corticosteroids; LABA, long-acting $\beta_{2}$-agonist; SGRQ, St George's Respiratory Questionnaire.

treatment groups. In the $\mathrm{A} / \mathrm{D}(+)$ group, the incidence (GLY vs placebo) of COPD worsening (7.4\% vs $13.3 \%)$, anxiety $(1.2 \%$ vs $5.3 \%)$ and headache $(1.2 \%$ vs $5.3 \%)$ was lower in the GLY treatment group compared to placebo. The incidence of dry mouth, a common AE observed with LAMA treatment, was low, occurring only in the A/D (-) group (placebo, $n=1$ [0.3\%]; GLY $25 \mu \mathrm{g}$ BID, $\mathrm{n}=4[1.1 \%])$.

The incidence of SAEs was higher in the A/D (+) group (7.4-9.3\%), compared with the A/D (-) group (2.0-4.8\%). The most commonly reported SAE was COPD worsening among the A/D (+) group (GLY: 2.5\%; Placebo: $4.0 \%$ ), and pneumonia in the A/D (-) group (GLY: 0\%; Placebo: 0.8\%).

\section{Discussion}

Anxiety and depression are common in patients with COPD, with growing evidence supporting a bidirectional relationship between $\mathrm{A} / \mathrm{D}$ disorders and $\mathrm{COPD}$, wherein one can impact the severity and prognosis of the other. ${ }^{5,7}$ Despite the high prevalence of $\mathrm{A} / \mathrm{D}$ among patients with COPD, ${ }^{21,22}$ there are limited data assessing the impact of these comorbidities on the efficacy (or effectiveness) and safety of bronchodilator therapy. In addition, studies in patients with A/D in non-respiratory diseases have shown a pattern of high placebo response with neuropsychiatric drugs. $^{23,24}$ However, there is a paucity of data characterizing the placebo response in patients with COPD and 


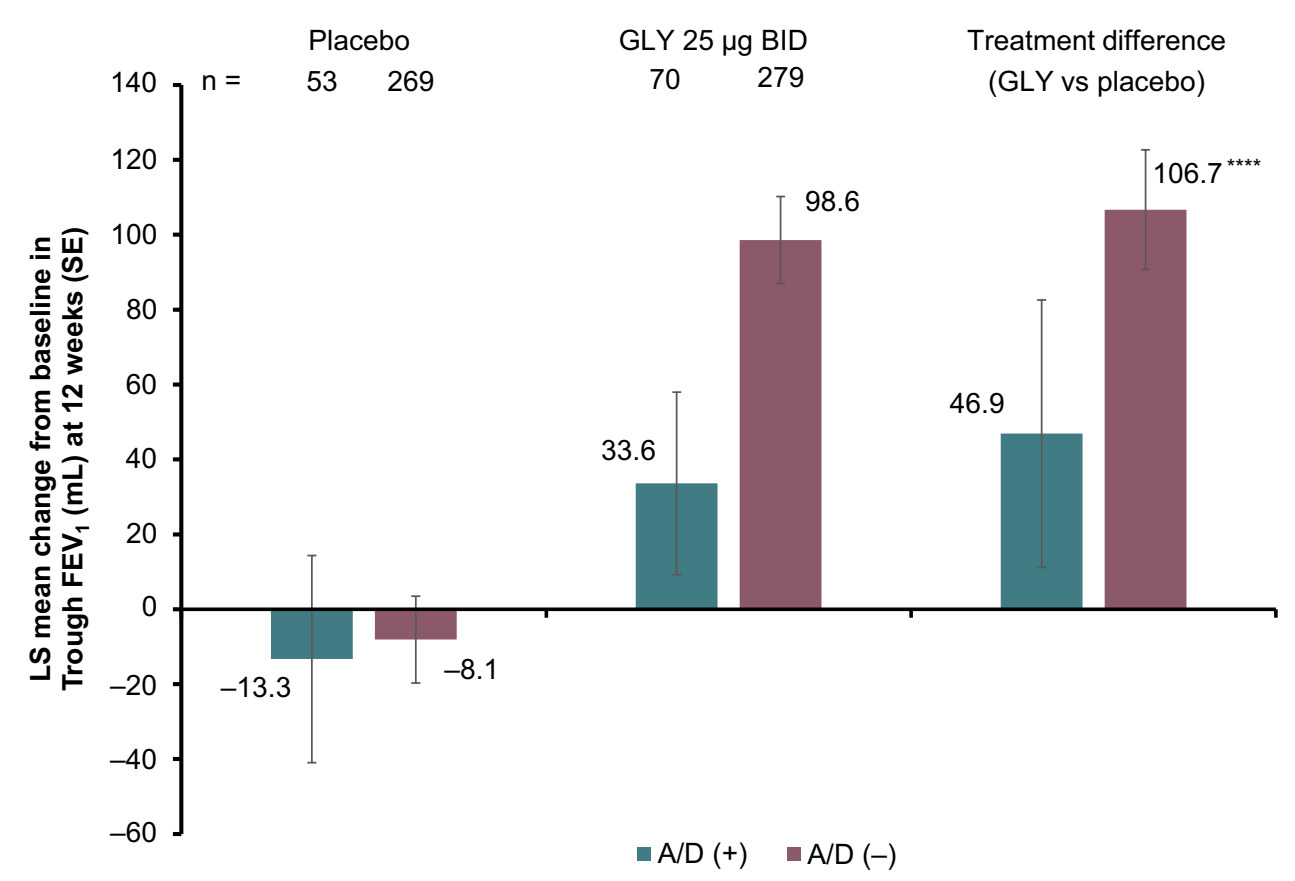

Figure 2 Pooled analysis of change from baseline in trough FEV at 12 weeks, by baseline comorbid anxiety and depression status (ITT population). Notes: $* * * * 00001$ vs Placebo. The $\mathrm{n}$ values represent the number of patients with on-treatment data at Week 12 .

Abbreviations: A/D (+), comorbid anxiety and depression; A/D (-), no comorbid anxiety and depression, or anxiety or depression alone; BID, twice daily; FEV 1 , forced expiratory volume in I second; GLY, nebulized glycopyrrolate; ITT, intent-to-treat; LS, least squares; SE, standard error.

comorbid A/D. Our study results suggest that treatment with GLY showed numerical improvements in treatment outcomes such as lung function $\left(\mathrm{FEV}_{1}\right)$ and HRQoL (SGRQ scores), compared with placebo regardless of baseline A/D status; however, significant improvements in these outcomes compared with placebo were only observed in the A/D (-) group. Of note, the A/D (+) group showed greater improvements from baseline in SGRQ total and domain scores compared with the A/D (-) group; however, there was also a high placebo response in the $\mathrm{A} / \mathrm{D}(+)$ group.

Comorbid A/D was observed in $18 \%$ of patients from the pooled GOLDEN 3 and 4 populations. This prevalence is slightly lower than that reported in literature, which ranges from $22 \%$ to $48 \% .^{13,14}$ This difference may be attributed to the self-reporting of $A / D$, which may have led to under-representation of the actual number of patients with comorbid A/D disorders in the population. However, baseline demographics and disease characteristics of $\mathrm{A} / \mathrm{D}(+)$ patients in this post hoc analysis were in agreement with previous studies. $5,10,25,26$ A high prevalence of A/D among females and younger patients was noted in the GOLDEN 3 and 4 studies (Table 2); while these differences in baseline demographics and disease characteristics, such as background
LABA use, may have contributed to the observed differences in lung function improvements between patients in the A/D (+) and A/D (-) groups, previous analyses of the results from GOLDEN 3 and 4 showed no differences in lung function improvements by gender, age, and background LABA use. ${ }^{27-29}$ The higher proportion of current smokers among patients with comorbid A/D and COPD is also consistent with the literature, ${ }^{5}$ and may be in part due to the greater difficulty of smoking cessation among patients with depression. ${ }^{30}$ The differences in lung function improvements between patients in the $\mathrm{A} / \mathrm{D}(+)$ and A/D (-) groups may have been impacted by smoking status in these patients; while there are no studies on the impact of smoking status on efficacy of treatment with nebulized GLY, a previous analysis of GLY inhalation powder delivered using a dry powder inhaler showed similar improvements among smokers and nonsmokers. ${ }^{31}$ Further analysis of the impact of smoking on treatment with nebulized GLY is needed.

Overall, treatment with GLY led to improvements in lung function and SGRQ relative to placebo independent of A/D status, although the magnitude and significance of these differences varied between the two groups. Lung function showed significant improvements with GLY compared with placebo in the A/D (-) group only; this may be 

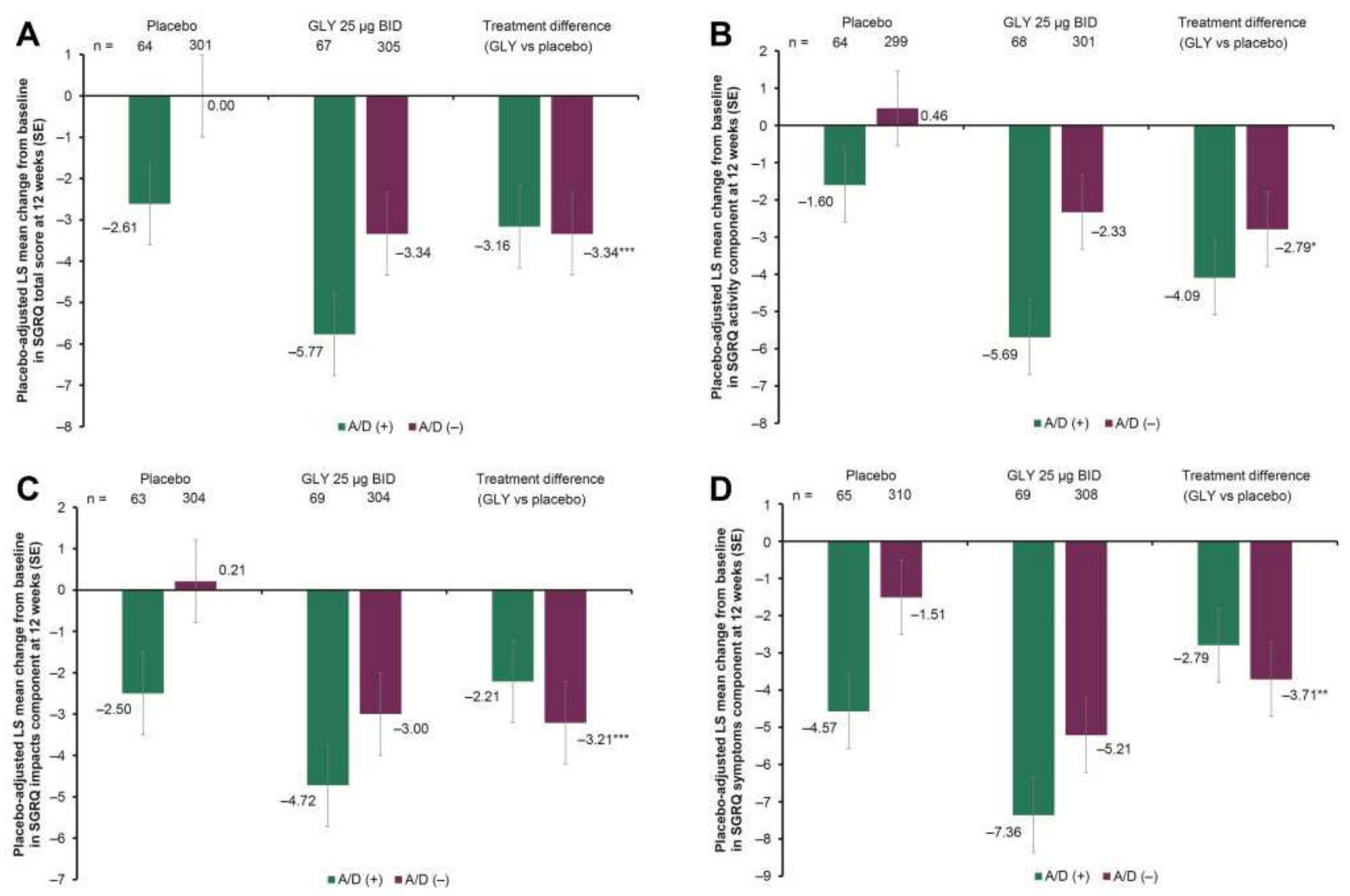

Figure 3 Pooled analysis of SGRQ change from baseline in (A) total score, (B) activity score, (C) impacts score, and (D) symptoms score at I2 weeks, by baseline comorbid anxiety and depression status (ITT population).

Notes: ${ }^{p}<0.05 ; * *_{p}<0.01 ; * * *<<0.001$ vs placebo. The $\mathrm{n}$ values represent the number of patients with on-treatment data at Week 12.

Abbreviations: A/D (+), comorbid anxiety and depression; A/D (-), no comorbid anxiety and depression, or anxiety or depression alone; BID, twice daily; GLY, nebulized glycopyrrolate; ITT, intent-to-treat; LS, least squares; SE, standard error; SGRQ, St George's Respiratory Questionnaire.

OR: 1.789

$(95 \% \mathrm{Cl}: 0.863,3.708)$

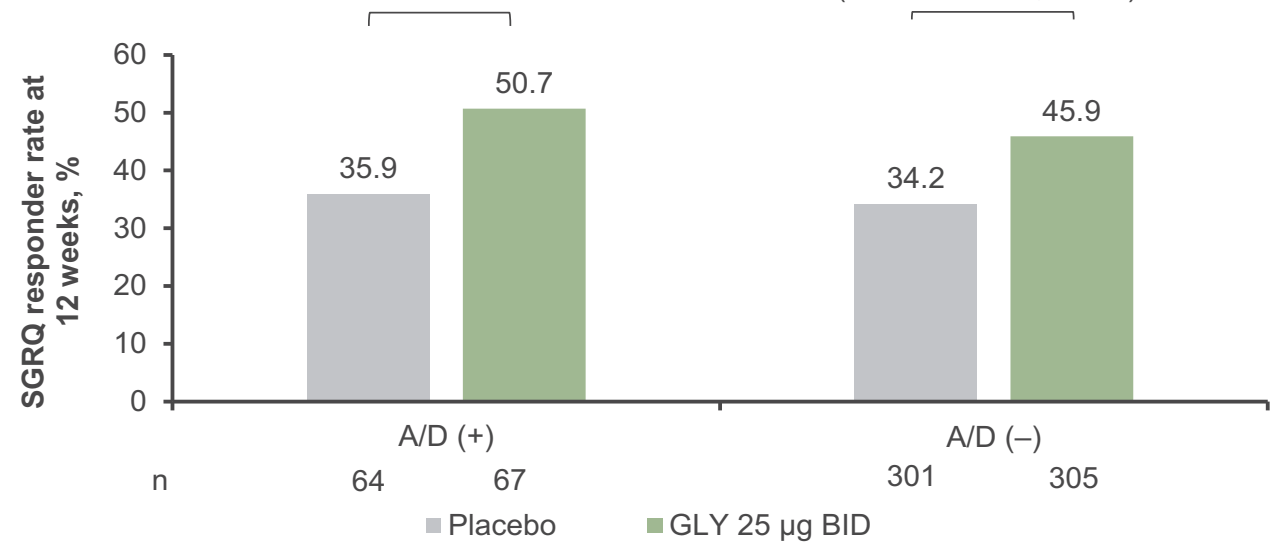

Figure 4 SGRQ responder rates at 12 weeks, by baseline comorbid anxiety and depression status (ITT population).

Notes: ${ }^{*} \mathrm{p}<0.01$ vs placebo. The $\mathrm{n}$ values represent the number of patients with on-treatment data at Week 12 .

Abbreviations: A/D (+), comorbid anxiety and depression; A/D (-), no comorbid anxiety and depression, or anxiety or depression alone; BID, twice daily; CI, confidence interval; GLY, nebulized glycopyrrolate; ITT, intent-to-treat; OR, odds ratio; SGRQ, St George's Respiratory Questionnaire. 
Table 3 Summary of AEs and SAEs, Including Individual AEs with Incidence $\geq 5 \%$ in Any Treatment Group, by Baseline Comorbid Anxiety and Depression Status (Safety Population)

\begin{tabular}{|c|c|c|c|c|}
\hline \multirow[t]{2}{*}{ Preferred Term, n (\%) } & \multicolumn{2}{|c|}{ A/D (+) } & \multicolumn{2}{|c|}{ A/D (-) } \\
\hline & Placebo $N=75$ & GLY $25 \mu g$ BID N=8I & Placebo $N=355$ & GLY $25 \mu$ B BID $N=350$ \\
\hline Any AE & $50(66.7)$ & $44(54.3)$ & I $75(49.3)$ & 143 (40.9) \\
\hline Cough & $8(10.7)$ & $8(9.9)$ & $28(7.9)$ & $22(6.3)$ \\
\hline COPD worsening & $10(13.3)$ & $6(7.4)$ & $27(7.6)$ & $22(6.3)$ \\
\hline Gastroenteritis & $4(5.3)$ & $\mathrm{I}(\mathrm{I} .2)$ & $2(0.6)$ & $\mathrm{I}(0.3)$ \\
\hline Anxiety & $4(5.3)$ & $I(I .2)$ & $0(0)$ & I (0.3) \\
\hline Headache & $4(5.3)$ & $\mathrm{I}(\mathrm{I} .2)$ & $6(1.7)$ & $6(1.7)$ \\
\hline Any SAE & $7(9.3)$ & $6(7.4)$ & $17(4.8)$ & $7(2.0)$ \\
\hline
\end{tabular}

Abbreviations: AE, adverse event; A/D (+), comorbid anxiety and depression; A/D (-), no comorbid anxiety and depression, or anxiety or depression alone; COPD, chronic obstructive pulmonary disease; BID, twice daily; GLY, nebulized glycopyrrolate; SAE, serious adverse event.

a result of the small sample size in the A/D (+) group, which may have led to larger variability of outcomes. However, the large difference in placebo-adjusted changes from baseline in $\mathrm{FEV}_{1}$ between groups suggests potential advantages of treatment with GLY in the A/D (-) group compared with the $\mathrm{A} / \mathrm{D}(+)$ group $(106.7 \mathrm{~mL}$ vs $46.9 \mathrm{~mL}$, respectively). Differences in patient characteristics at baseline may also have contributed to the absence of significant improvement in the $\mathrm{A} / \mathrm{D}(+)$ group; although baseline $\mathrm{FEV}_{1}$ was similar across groups, the proportion of women and current smokers was greater in the $\mathrm{A} / \mathrm{D}(+)$ group compared with $\mathrm{A} / \mathrm{D}(-)$ group. The low $\mathrm{FEV}_{1}$ response observed in the $\mathrm{A} / \mathrm{D}(+)$ group may also be explained by the observation that poor lung function and $\mathrm{A} / \mathrm{D}$ symptoms are often interrelated. ${ }^{7}$ In a study of 200 patients with asthma, lung function was significantly worse among patients with $\mathrm{A} / \mathrm{D}$ symptoms, compared to those without A/D symptoms. ${ }^{32}$ Decreased lung function can also result in mental health and emotional problems; in an analysis of 6913 participants, impairments in lung function were significantly associated with anxiety and depression. ${ }^{33}$ The role of $\mathrm{A} / \mathrm{D}$ in $\mathrm{COPD}$ progression is further supported by the observation that patients with COPD who are treated for $\mathrm{A} / \mathrm{D}$ disorders show improvements in both lung function and PROs. ${ }^{34}$ Comorbid A/D in COPD may also confound pulmonary function tests in a laboratory setting; in patients with lung disease, an association between $\mathrm{A} / \mathrm{D}$ and respiratory symptoms has been reported. ${ }^{35}$ Another possibility that may have confounded the $\mathrm{FEV}_{1}$ outcomes among patients in the $\mathrm{A} / \mathrm{D}(+)$ group is that patients with both anxiety and depression may have greater problems performing forced expiratory maneuvers properly, and these suboptimal efforts may have influenced the observed outcomes. Patients with A/D are also three-times more likely to be non-adherent to their medications compared to A/D (-) patients. ${ }^{36}$ While compliance/adherence was not assessed for the individual groups in this analysis, a combination of these factors may provide insight into the lack of significance in lung function improvements in the A/D (+) group compared with the A/D (-) group. ${ }^{37,38}$ Additional analyses in patients with COPD and comorbid $\mathrm{A} / \mathrm{D}$ are needed to understand the differences in lung function improvement with treatment.

SGRQ total and domain scores were $\sim 7-10$ points higher at baseline in the A/D (+) group compared to the A/D (-) group, indicating worse baseline PROs in the $\mathrm{A} / \mathrm{D}(+)$ group; this has been observed in other studies. ${ }^{39}$ This may be related to worse symptoms, acute exacerbations, decreased exercise tolerance and dyspnea observed among patients with COPD and comorbid A/D. ${ }^{5,10,21,22}$ We consistently observed numerical improvements in both SGRQ total and domain scores in the $\mathrm{A} / \mathrm{D}(+)$ group (Figure 3). This is consistent with the observation that patients with COPD who are treated for $\mathrm{A} / \mathrm{D}$ show improvements in PROs. ${ }^{34}$ However, despite numerical improvements in SGRQ total scores in the A/D (+) group, a significant difference with GLY was not observed when compared with placebo; this is likely due to a high placebo response observed in the A/D (+) group. This high placebo response was notably high in the SGRQ symptoms domain, where MCID of -4.57 was observed in the A/D (+) group (Figure 3D) not with other domains. Similar placebo effects have been observed in clinical trials of antidepressants; these increased responses to placebo diminish the differences observed with the active drug, often leading to failure of these trials. ${ }^{23,24} \mathrm{~A}$ meta-analysis of antidepressant trials has shown that a high placebo response rather than low 
medication response can lead to trial failure. ${ }^{23}$ Therefore, it is likely that GLY improved SGRQ scores in the A/D (+) groups; however, it is masked by the high placebo response, resulting in the absence of a significant improvement in this group.

The safety profile of GLY was generally similar between the two A/D groups, although the incidence of AEs and SAEs among patients treated with GLY was higher in the A/D (+) group, compared with the A/D (-) group. This may reflect mechanistic links between $\mathrm{A} / \mathrm{D}$ disorders and COPD; alternatively, these differences may be due to demographic differences or differences in the perception of health status by patients with different $\mathrm{A} / \mathrm{D}$ disorder status. Consistent with the interdependence between COPD and A/D disorders, patients treated with GLY had lower overall incidence of AEs and SAEs, as well as incidences of the most common AEs, compared with placebo. Other AEs that occurred to a greater extent among A/D (+) patients included cough and COPD worsening, both of which may have been impacted by the higher proportion of current smokers in the A/D (+) group. In the $\mathrm{A} / \mathrm{D}(+)$ group, the incidence of headache and anxiety was also lower compared to placebo. This suggests that GLY can be effective among patients with comorbid $\mathrm{A} / \mathrm{D}$ as it can improve lung function and decrease the incidence of $\mathrm{A} / \mathrm{D}$ disorder-related AEs (eg, headache and anxiety).

Limitations of the study include the post hoc nature of the patient stratification in this analysis as well as the lack of adjustment for multiplicity. The difference in the number of patients in each sub-group, the high prevalence of active smokers in the A/D (+) vs A/D (-) group, as well as the patient demographics (eg, predominantly white patients) may have contributed to some of the variability observed in the reported outcomes. In addition, the self-reporting of $\mathrm{A} / \mathrm{D}$, rather than clinical adjudication, may have resulted in under-reporting of A/D disorders, as reported previously. ${ }^{40}$ Further, caution is required in interpretation of the data as we have not examined the severity of depression or anxiety symptoms in patients with COPD using screening or clinical diagnostic tools. Hence, clinical trials that utilize well-validated A/D diagnostic tools as a predetermined stratification criterion are needed to better assess the impact of comorbid A/D disorders on the efficacy and safety of bronchodilators in patients with COPD.

\section{Conclusions}

In this post hoc analysis, treatment with GLY $25 \mu \mathrm{g}$ BID for 12 weeks showed numerical improvements in $\mathrm{FEV}_{1}$ and SGRQ scores, regardless of comorbid A/D; however, statistically significant improvement in both assessments with GLY compared with placebo was only observed in the A/D (-) group. GLY was well tolerated and, importantly, resulted in improvements in A/D-related AEs (eg, headache) compared with placebo. These results highlight the importance of considering underlying comorbidities including $\mathrm{A} / \mathrm{D}$ in patients with $\mathrm{COPD}$ as potential modifiers of treatment response and the need for well-designed, randomized controlled studies on the influence of these comorbidities on COPD therapies. In addition, these results provide important insights into treatment recommendations and follow-up for clinicians with patients with COPD and comorbid anxiety and depression.

\section{Data Sharing Statement}

Sunovion Pharmaceuticals Inc. is part of a clinical trial data sharing consortium that facilitates access for qualified researchers to selected anonymized clinical trial data. For up-to-date information on data availability please visit https://www.clinicalstudydatarequest.com/Study-Sponsors. aspx and click on Sunovion.

\section{Acknowledgments}

The authors would like to thank Shane Hornibrook from Sarepta Therapeutics Inc., Diane Hall from Sunovion Pharmaceuticals Inc., and Rajeshwari Sammishetty from Sage Therapeutics Inc., for support with statistical analyses performed. This post hoc analysis was supported by funding from Sunovion Pharmaceuticals Inc. Medical writing support was provided by Hashem Dbouk, PhD and Dhivya Ramalingam, PhD of Ashfield MedComms, an Ashfield Health company, and funded by Sunovion Pharmaceuticals Inc.

\section{Author Contributions}

All authors were involved at all stages of manuscript development and have approved the final draft. All authors contributed to data analysis, drafting or revising the article, have agreed on the journal to which the article will be submitted, gave final approval of the version to be published, and agree to be accountable for all aspects of the work. 


\section{Disclosure}

NAH received honoraria for serving as a consultant or advisory boards for GlaxoSmithKline, Sanofi, Regeneron, Genentech, Novartis, Boehringer Ingelheim, Astra Zeneca, Teva, Amgen, and Mylan Pharmaceuticals. His institution receives research grant support from GlaxoSmithKline, Sanofi, Genentech, Gossamer Bio, Boehringer Ingelheim, Novartis, and AstraZeneca. AMY received an honorarium for consultation fees from AstraZeneca. AOG was an employee of Sunovion Pharmaceuticals Inc. at the time of the study and is currently an employee of Alexion Pharmaceuticals. MT, TG, SSh, and SSa are employees of Sunovion Pharmaceuticals Inc. The authors report no other conflicts of interest in this work.

\section{References}

1. Global Initiative for Chronic Obstructive Lung Disease (GOLD). Global strategy for the diagnosis, management and prevention of COPD. Available from: http://goldcopd.org/. Accessed May 20, 2019.

2. Divo M, Cote C, de Torres JP, et al. Comorbidities and risk of mortality in patients with chronic obstructive pulmonary disease. Am J Respir Crit Care Med. 2012;186(2):155-161. doi:10.1164/ rccm.201201-0034OC

3. Brown JP, Martinez CH. Chronic obstructive pulmonary disease comorbidities. Curr Opin Pulm Med. 2016;22(2):113-118. doi:10.10 97/MCP.0000000000000241

4. Tsai TY, Livneh H, Lu MC, Tsai PY, Chen PC, Sung FC. Increased risk and related factors of depression among patients with COPD: a population-based cohort study. BMC Public Health. 2013;13:976. doi:10.1186/1471-2458-13-976

5. Yohannes AM, Kaplan A, Hanania NA. COPD in primary care: key considerations for optimized management: anxiety and depression in chronic obstructive pulmonary disease: recognition and management. J Fam Pract. 2018;67(2 Suppl):S11-S18.

6. Zhang MW, Ho RC, Cheung MW, Fu E, Mak A. Prevalence of depressive symptoms in patients with chronic obstructive pulmonary disease: a systematic review, meta-analysis and meta-regression. Gen Hosp Psychiatry. 2011;33(3):217-223. doi:10.1016/j.genhosppsych. 2011.03.009

7. Atlantis E, Fahey P, Cochrane B, Smith S. Bidirectional associations between clinically relevant depression or anxiety and COPD: a systematic review and meta-analysis. Chest. 2013;144 (3):766-777. doi:10.1378/chest.12-1911

8. Fan VS, Giardino ND, Blough DK, Kaplan RM, Ramsey SD, Nett Research G. Costs of pulmonary rehabilitation and predictors of adherence in the National Emphysema Treatment Trial. COPD. 2008;5(2):105-116. doi:10.1080/15412550801941190

9. Dalal AA, Shah M, Lunacsek O, Hanania NA. Clinical and economic burden of depression/anxiety in chronic obstructive pulmonary disease patients within a managed care population. COPD. 2011;8 (4):293-299. doi:10.3109/15412555.2011.586659

10. Maurer J, Rebbapragada V, Borson S, et al. Anxiety and depression in COPD: current understanding, unanswered questions, and research needs. Chest. 2008;134(4):43S-56S. doi:10.1378/chest.08-0342

11. Yohannes AM, Dryden S, Hanania NA. The responsiveness of the anxiety inventory for respiratory disease scale following pulmonary rehabilitation. Chest. 2016;150(1):188-195. doi:10.1016/j.chest.20 16.02 .658
12. Frei A, Muggensturm P, Putcha N, et al. Five comorbidities reflected the health status in patients with chronic obstructive pulmonary disease: the newly developed COMCOLD index. J Clin Epidemiol. 2014;67(8):904-911. doi:10.1016/j.jclinepi.2014.03.005

13. Phan T, Carter O, Waterer G, et al. Determinants for concomitant anxiety and depression in people living with chronic obstructive pulmonary disease. J Psychosom Res. 2019;120:60-65. doi:10.1016/ j.jpsychores.2019.03.004

14. Putman-Casdorph H, McCrone S. Chronic obstructive pulmonary disease, anxiety, and depression: state of the science. Heart Lung. 2009;38(1):34-47. doi:10.1016/j.hrtlng.2008.02.005

15. Cully JA, Graham DP, Stanley MA, et al. Quality of life in patients with chronic obstructive pulmonary disease and comorbid anxiety or depression. Psychosomatics. 2006;47(4):312-319. doi:10.1176/appi. psy.47.4.312

16. Sunovion Pharmaceuticals Inc. Lonhala Magnair (glycopyrrolate) inhalation solution: highlights of prescribing information. 2017.

17. Kerwin E, Donohue JF, Goodin T, Tosiello R, Wheeler A, Ferguson GT. Efficacy and safety of glycopyrrolate/eFlow ${ }^{\circledR}$ CS (nebulized glycopyrrolate) in moderate-to-very-severe COPD: results from the glycopyrrolate for obstructive lung disease via electronic nebulizer (GOLDEN) 3 and 4 randomized controlled trials. Respir Med. 2017;132:238-250. doi:10.1016/j.rmed.2017.07. 011

18. US Department of Health and Human Services (DHHS). National Center for Health Statistics. Third National Health and Nutrition Examination Survey 1988-1994, NHANES III Raw Spirometry Data File (Series 11, No. 9A). Hyattsville, MD: Centers for Disease Control and Prevention; 2001.

19. Miller MR. ATS/ERS task force. Standardisation of spirometry. Eur Respir J. 2005;26(2):319-338. doi:10.1183/ 09031936.05.00034805

20. Jones PW. St. George's respiratory questionnaire: MCID. COPD. 2005;2(1):75-79. doi:10.1081/copd-200050513

21. Di Marco F, Verga M, Reggente M, et al. Anxiety and depression in COPD patients: the roles of gender and disease severity. Respir Med. 2006;100(10):1767-1774. doi:10.1016/j.rmed.2006.01.026

22. Vogele C, von Leupoldt A. Mental disorders in chronic obstructive pulmonary disease (COPD). Respir Med. 2008;102(5):764-773. doi:10.1016/j.rmed.2007.12.006

23. Rutherford BR, Roose SP. A model of placebo response in antidepressant clinical trials. Am J Psychiatry. 2013;170(7):723-733. doi:10.1176/appi.ajp.2012.12040474

24. Kirsch I. Antidepressants and the placebo effect. Z Psychol. 2014;222 (3):128-134. doi:10.1027/2151-2604/a000176

25. Hanania NA, Mullerova H, Locantore NW, et al. Determinants of depression in the ECLIPSE chronic obstructive pulmonary disease cohort. Am J Respir Crit Care Med. 2011;183(5):604-611. doi:10.1164/rccm.201003-0472OC

26. World Health Organization. Depression and other common mental disorders: global health estimates. Available from: https://apps.who. int/iris/bitstream/handle/10665/254610/WHO-MSD-MER-2017. 2-eng.pdf. Accessed June 06, 2019.

27. Ohar J, Tosiello R, Goodin T, Sanjar S. Efficacy and safety of a novel, nebulized glycopyrrolate for the treatment of COPD: effect of baseline disease severity and age; pooled analysis of GOLDEN 3 and GOLDEN 4. Int J COPD. 2019;14:27-37. doi:10.2147/COPD.S184808

28. Ohar J, Ozol-Godfrey A, Goodin T, Sanjar S. Effect of gender on lung function and patient-reported outcomes in patients with COPD receiving nebulized glycopyrrolate. Int J COPD. 2020;15:995-1004. doi:10.2147/COPD.S24030

29. Kerwin EM, Tosiello R, Price B, Sanjar S, Gooding T. Effect of background long-acting beta 2-agonist therapy on the efficacy and safety of a novel, nebulized glycopyrrolate in subjects with moderate-to-very-severe COPD. Int J COPD. 2018;13:2917-2929. doi:10.2147/COPD.S172408 
30. Berlin I, Covey LS. Pre-cessation depressive mood predicts failure to quit smoking: the role of coping and personality traits. Addiction. 2006;101(12):1814-1821. doi:10.1111/j.1360-0443.200 6.01616.x

31. Tashkin DP, Goodin T, Bowling A, et al. Effect of smoking status on lung function, patient-reported outcomes, and safety among COPD patients treated with glycopyrrolate inhalation powder: pooled analysis of GEM1 and GEM2 studies. Respir Res. 2019;20:135. doi:10.1186/s12931-019-1112-0

32. Labor S, Labor M, Juric I, Vuksic Z. The prevalence and pulmonary consequences of anxiety and depressive disorders in patients with asthma. Coll Antropol. 2012;36(2):473-481.

33. Goodwin RD, Chuang S, Simuro N, Davies M, Pine DS. Association between lung function and mental health problems among adults in the United States: findings from the First National Health and Nutrition Examination Survey. Am J Epidemiol. 2007;165 (4):383-388. doi:10.1093/aje/kwk026

34. Momtaz OM, Rabei SM, Tawfike NR, Hasan AA. Effect of treatment of depression and anxiety on physiological state of severe COPD patients. Egypt J Chest Dis Tuberc. 2015;64(1):29-34. doi:10.1016/j. ejcdt.2014.08.006

35. Chetta A, Foresi A, Marangio E, Olivieri D. Psychological implications of respiratory health and disease. Respiration. 2005;72 (2):210-215. doi: $10.1159 / 000084056$
36. DiMatteo MR, Lepper HS, Croghan TW. Depression is a risk factor for noncompliance with medical treatment: meta-analysis of the effects of anxiety and depression on patient adherence. Arch Intern Med. 2000;160(14):2101-2107. doi:10.1001/archinte.160.14.2101

37. Bosley CM, Corden ZM, Rees PJ, Cochrane GM. Psychological factors associated with use of home nebulized therapy for COPD. Eur Respir J. 1996;9(11):2346-2350. doi:10.1183/09031936.96.09112346

38. Yohannes AM, Alexopoulos GS. Pharmacological treatment of depression in older patients with chronic obstructive pulmonary disease: impact on the course of the disease and health outcomes. Drugs Aging. 2014;31(7):483-492. doi:10.1007/s40266-014-0186-0

39. Yohannes AM, Mullerova H, Hanania NA, et al. Long-term course of depression trajectories in patients with COPD: a 3-year follow-up analysis of the evaluation of COPD longitudinally to identify predictive surrogate endpoints cohort. Chest. 2016;149(4):916-926. doi:10.1016/j.chest.2015.10.081

40. Yohannes AM, Connolly MJ, Baldwin RC. A feasibility study of antidepressant drug therapy in depressed elderly patients with chronic obstructive pulmonary disease. Int J Geriatr Psychiatry. 2001;16 (5):451-454. doi:10.1002/gps.461

\section{Publish your work in this journal}

The International Journal of COPD is an international, peer-reviewed journal of therapeutics and pharmacology focusing on concise rapid reporting of clinical studies and reviews in COPD. Special focus is given to the pathophysiological processes underlying the disease, intervention programs, patient focused education, and self management protocols. This journal is indexed on PubMed Central, MedLine and CAS. The manuscript management system is completely online and includes a very quick and fair peer-review system, which is all easy to use. Visit http://www.dovepress.com/testimonials.php to read real quotes from published authors. 